\title{
Naturally occurring bacteriophages lyse a large proportion of canine and feline uropathogenic Escherichia coli isolates in vitro
}

\author{
T. Freitag ${ }^{a, *}$, R.A. Squires ${ }^{a}$, J. Schmid ${ }^{b}$ \\ a Institute of Veterinary, Animal and Biomedical Sciences, Massey University, Palmerston North, New Zealand \\ ${ }^{\mathrm{b}}$ Institute of Molecular Biosciences, Massey University, Palmerston North, New Zealand
}

Accepted 4 September 2007

\begin{abstract}
We investigated the feasibility of bacteriophage therapy to combat canine and feline Escherichia coli urinary tract infections (UTIs) by testing the in vitro lytic ability of 40 naturally occurring bacteriophages on 53 uropathogenic E. coli (UPEC). The mean number of UPEC strains lysed by an individual bacteriophage was $21 / 53(40 \%$, range $17-72 \%)$. In total, 50/53 (94\%) of the UPEC strains were killed by one or more of the bacteriophages. Ten bacteriophages lysed $\geqslant 51 \%$ of UPEC strains individually and $92 \%$ of UPEC strains as a group. Electron microscopy and DNA sequencing of 5 'promising' bacteriophages revealed that 4 bacteriophages belonged to the lytic T4-like genus, while one displayed morphologic similarity to temperate P2-like bacteriophages. Overall, these results indicate that the majority of UPEC are susceptible to lysis by naturally occurring bacteriophages. Thus, bacteriophages show promise as therapeutic agents for treatment of canine and feline E. coli UTIs.
\end{abstract}

(C) 2007 Elsevier Ltd. All rights reserved.

Keywords: Escherichia coli; Cat; Dog; Bacteriophage therapy; Uropathogenic; Urinary tract infection

\section{Introduction}

Uropathogenic Escherichia coli (UPEC) is the most important infectious cause of urinary tract disease in dogs, cats and people (Foxman, 2002; Ling, 2000; Russo and Johnson, 2003). UPEC infections, once diagnosed, are usually managed with antibiotic therapy (Bartges, 2005). However, antibiotic resistant forms of UPEC have emerged and pose problems in many parts of the world (Cohn et al., 2003; Manges et al., 2001; Mulvey et al., 2001). Even UPEC that are susceptible to antibiotics in vitro may persist in an infected host, or in its immediate environment, despite lengthy antibiotic treatment (Freitag et al., 2006; Schilling et al., 2002; Seguin et al., 2003). In dogs and cats,

\footnotetext{
* Corresponding author. Present address: Department of Small Animal Clinical Studies, University Veterinary Hospital, University College Dublin, Belfield, Dublin 4, Ireland. Tel.: +353 1716 6015; fax: +353 1 7166023 .

E-mail address: Thurid.Freitag@ucd.ie (T. Freitag).
}

persistence or relapse of urinary tract infections (UTIs) has recently been shown to occur more often than had previously been realised (Drazenovich et al., 2004; Freitag et al., 2006). When persistence or relapse is recognised, antibiotic therapy is often extended. However, it is sometimes difficult to cure affected patients. Therapy with bacteriophages (phages) - viruses that can infect and kill bacteria - may be used to supplement or substitute antibiotic therapy (Alisky et al., 1998). Phage therapy of human UTIs dates back to early last century (reviewed by Raettig, 1958). In more recent years, phages have been used successfully to prevent or cure $E$. coli meningitis, pneumonia and gastroenteritis in chicken, mice and calves (Barrow et al., 1998; Huff et al., 2003, 2004; Smith and Huggins, 1982, 1983). Furthermore, recent clinical observations from the former Soviet Union and Poland indicate that phages can be used successfully to resolve antibiotic resistant UTIs in humans (Perepanova et al., 1995; Slopek et al., 1987; Weber-Dabrowska et al., 2000). These clinical observations and experimental studies are encouraging. Nonetheless, the 
feasibility of phage therapy for management of UTI, particularly in dogs and cats, remains to be investigated.

In this study, we tested the hypothesis that a variety of phages able to lyse canine and feline UPEC can readily be found in the environment. The ability of collected phages to cause lysis in vitro was tested on 53 UPEC strains and 7 faeces-derived E. coli strains from dogs and cats. When lysis profiles suggested that phages were promising candidates for an in vivo trial, phages were subjected to further morphological and genetic studies, using electron microscopy and DNA sequencing.

\section{Materials and methods}

\subsection{Strain collection}

Between January 2002 and April 2004, 31 UPEC strains from dogs and 22 UPEC strains from cats were obtained from 4 New Zealand animal health laboratories. Each strain was cultured from urine derived from individual animals at a different place or time. Urine collection was done by antepubic cystocentesis, a method previously shown to minimise contamination with cutaneous and faecal organisms (Comer and Ling, 1981). Fifty-one of these strains, which were assessed further by molecular means, differed either in possession of virulence factor gene markers, Pulsed-Field Gel Electrophoresis banding patterns or both (Freitag et al., 2005). The genomes of the 2 remaining UPEC strains were not assessed. However, the UPEC strains are likely to be epizootiologically unrelated. They were isolated 14 months apart from a dog and a cat, respectively, that lived in different geographic regions of New Zealand. Seven faecal $E$. coli isolates were collected from stool samples of 4 dogs and 3 cats without clinical signs of UTI or gastrointestinal disease. After acquisition, all UPEC and faecal $E$. coli isolates were biochemically confirmed to belong to the species E. coli (Quinn et al., 1994). Isolates were stored in $15 \%$ glycerol broth at $-70{ }^{\circ} \mathrm{C}$ until use.

\subsection{Preparation of phage stocks}

Phages were isolated from Palmerston North sewage according to a method published by Biswas et al. (2002), using centrifugation, polyethylene glycol (PEG) 8000 precipitation, chloroform extraction and propagation on selected UPEC strains. Propagation of phages was initially performed on 21 canine and 21 feline UPEC, chosen at random, using the double-layer technique (Ackermann and DuBow, 1987). In detail, a $100 \mu 1$ aliquot of processed sewage was added to a $100 \mu \mathrm{l}$ aliquot of each selected E. coli culture, grown in Luria Bertani (LB) broth at $37^{\circ} \mathrm{C}$ overnight. After incubation for $20 \mathrm{~min}$ at $37^{\circ} \mathrm{C}$, the mixture was added to $2 \mathrm{ml}$ molten LB top agar (LB broth containing $0.65 \%$ agarose, kept at $50{ }^{\circ} \mathrm{C}$ until use), mixed gently and poured onto $55 \mathrm{~mm} \mathrm{LB}$ agar plates. After overnight incubation at $37^{\circ} \mathrm{C}$, one well-separated phage plaque was picked from each plate that displayed plaques. Each of the picked plaques was separately suspended in $1 \mathrm{ml} \mathrm{SM}$ buffer (Sambrook and Russell, 2001). Harvested phages were plaque purified on their target $E$. coli isolates by repeating the double-layer technique 2 more times, using the newly obtained phage suspension instead of processed sewage. Small-scale liquid cultures and large-scale lysates of purified phages were prepared according to standard methods (Sambrook and Russell, 2001). Subsequently, phage stock solutions were prepared by PEG precipitation and chloroform extraction of large-scale phage lysates (Sambrook and Russell, 2001). Phage stock titres were determined by serial dilution and plaque assay, counting the plaque-forming units on the strain on which they had been propagated (Ackermann and DuBow, 1987). Stocks containing $\geqslant 10^{7}$ phages $/ \mathrm{ml}$ were considered appropriate for further analysis. Phage stocks were stored in $10 \mathrm{ml} \mathrm{SM}$ buffer aliquots containing $1 \%(\mathrm{v} / \mathrm{v})$ chloroform at $4{ }^{\circ} \mathrm{C}$ until further use.

\subsection{Bacteriophage lysis}

The lysis experiment was designed to test the ability of phages to lyse strains from the E. coli collection. Each phage was tested separately on each bacterial strain in the collection. LB broth cultures of all bacterial strains of the collection (53 UPEC and 7 faecal E. coli) were prepared according to standard methods (Quinn et al., 1994). Lysis was initially tested using a modified macroplaque technique (MMT; Sambrook and Russell, 2001). In detail, $200 \mu 1$ of each $E$. coli culture in turn was mixed with $1 \mathrm{ml}$ molten LB top agar and plated onto a layer of LB agar. Phages were transferred from the phage stock solution to the freshly plated culture using sterile wooden toothpicks. The toothpicks were dipped into phage stock solution, gently swirled to allow adherence of phage particles, and pierced several times into the freshly plated bacterial culture. After overnight incubation at $37^{\circ} \mathrm{C}$, plates were checked for evidence of clear zones of lysis around the toothpick marks. When lysis was present, a positive result was declared. The MMT was compared with the standard double-layer plating technique (see above) on 30 randomly chosen bacterial cultures. Positive results of the MMT were $100 \%$ in accord with results of the standard plating technique. When a zone of lysis was not clearly visible using the MMT (i.e. lysis $\leqslant 1 \mathrm{~mm}$ around the toothpick mark), the phage's ability to lyse the bacterial strain was further tested using a standard double-layer plating procedure. After overnight incubation at $37^{\circ} \mathrm{C}$, plates were observed for presence or absence of plaques. When plaques were present, a positive result was declared. Absence of plaques was interpreted as a negative result.

\subsection{Electron microscopy (EM)}

EM was performed on 5 phages selected from the phage collection on the basis of a promising lysis profile. A stan- 
dard laboratory T4 phage preparation was used for calibration. Ten $\mathrm{ml}$ of the respective phage stock solutions was concentrated by ultracentrifugation at $30,000 \mathrm{~g}$ for $2 \mathrm{~h}$ at $4{ }^{\circ} \mathrm{C}$ (SS 34 rotor, Sorvall RC 5C, Thermo EC, Waltham, MA, USA). Phage pellets were carefully resuspended in $1 \mathrm{ml} \mathrm{SM}$ buffer, and kept on ice until EM was performed. For each phage EM study, 1 drop of the prepared phage concentrate was placed on Parafilm $\mathbf{M}^{\circledR}$ (Brand Scientific Pty Ltd., Silverwater, NSW, Australia). A formvarcarbon-coated copper grid (200 mesh, Agar Brand, Agar Scientific, Stansted, Essex, UK) was floated on top of the phage concentrate for 4.5-6 min, blotted dry and stained with $2 \%$ uranyl acetate (UA; $\mathrm{pH} 4.2$ ) or phosphotungstate (pH 7.0) for 4.5-6 min. The copper grid was blotted dry and studied under a Philips 201C transmission electron microscope (Philips, Eindhoven, Holland) using an accelerating voltage of $60 \mathrm{kV}$. For each of the 5 selected phage strains and the T4 control, phage size was obtained by averaging measurements of $>20$ phage particles photographed at a magnification of $72,100 \times$ normal size. Measured sizes were compared with published sizes for $\mathrm{T} 4$ (Büchen-Osmond, 2006).

\subsection{Sequencing of bacteriophage DNA fragments}

Four phages that morphologically resembled T4-like phages were subjected to PCR analysis and DNA sequencing of the amplified tail tube glycoprotein gene 18 fragment to compare these phages to phylogenetically well-characterised phages (Tetart et al., 2001). Bacteriophage DNA was extracted and purified from stock concentrates using a commercial phage DNA extraction kit (Qiagen Pty Ltd., Doncaster, Victoria, Australia). PCR was done in a $25 \mu \mathrm{l}$ reaction volume containing $2 \mathrm{mM} \mathrm{MgSO} 4,0.2 \mathrm{mM}$ each dNTP, $0.4 \mu \mathrm{M}$ of each primer FT18-N2 and FT18C3 (Tetart et al., 2001), $1 \times$ buffer, 1 U Platinum ${ }^{\circledR} P f x$ DNA Polymerase (Invitrogen, Auckland, NZ) and $50 \mathrm{ng}$ template DNA. Cycling consisted of initial denaturation $\left(2 \mathrm{~min}\right.$ at $\left.94{ }^{\circ} \mathrm{C}\right)$ followed by a primary cycle period $\left(10 \times\left\{30 \mathrm{~s}\right.\right.$ at $94{ }^{\circ} \mathrm{C} ; 15 \mathrm{~s}$ at $58^{\circ} \mathrm{C} ; 50 \mathrm{~s}$ at $\left.\left.68^{\circ} \mathrm{C}\right\}\right)$, a secondary cycle period $\left(20 \times\left\{30 \mathrm{~s}\right.\right.$ at $94{ }^{\circ} \mathrm{C} ; 15 \mathrm{~s}$ at $56^{\circ} \mathrm{C} ; 45 \mathrm{~s}$ at $\left.\left.68{ }^{\circ} \mathrm{C}\right\}\right)$ and a final extension $\left(2 \mathrm{~min}\right.$ at $\left.68^{\circ} \mathrm{C}\right)$. The amplified DNA fragment was separated by gel electrophoresis, excised from the gel and purified using a commercial gel extraction kit (Qiagen Pty Ltd., Doncaster, Victoria, Australia). To increase the yield of phage DNA for sequencing purposes, the PCR reaction was repeated in a second round using the purified DNA fragment as template. Subsequently, DNA fragments were purified with a PCR purification kit (Qiagen Pty Ltd., Doncaster, Victoria, Australia). Sequencing was done with an ABI 3730 Genetic Analyzer, using a BigDye ${ }^{\mathrm{TM}}$ Terminator Version 3.1 Ready Reaction Cycle Sequencing kit (Applied Biosystems Inc., Foster City, CA, USA). Obtained nucleotide sequences were compared with previously published nucleotide sequences of phages that had been characterised in a previous phylogenetic study (Tetart et al., 2001). To display relationships between the sequences, a neighbour-joining tree was created using the Clustal-W aligned sequences (Chenna et al., 2003) using the software PAUP* 4.0 (Swofford, 2003).

\subsection{Statistical analysis}

The $z$-test of proportions was used to test whether the proportion undergoing lysis was related to the category of E. coli (i.e. UPEC or faecal E. coli; Dawson and Trapp, 1994). Results of $z$-test were adjusted for problems of multiplicity using Holm's step-down procedure (Ludbrook, 1998).

\subsection{Nucleotide sequence accession numbers}

The nucleotide sequences of the central portion of gene 18 from phages 1-4 have been deposited in the GenBank database under accession numbers DQ647771-DQ647774.

\section{Results}

\subsection{Phage isolation}

Phage isolation was attempted from processed sewage using 21 canine and 21 feline UPEC strains. Plaques were observed on 40 of the 42 UPEC strains after overnight incubation. No plaques formed on two of the canine UPEC strains.

\subsection{High susceptibility of UPEC to phage}

Each phage had a unique host range. Individual phages lysed a mean of 21.2/53 (40\%) UPEC strains in the collection (range $17-70 \%$, median $38 \%$ ). The 10 phages with the broadest host range each lysed at least $27 / 53(51 \%)$ of the UPEC strains (Fig. 1). Twelve UPEC strains (5 canine and 7 feline) were lysed by all of these 10 phages. As a group, the 10 phages with the broadest host range lysed 49/53 (92\%) UPEC strains. All but 3 of the 53 UPEC strains $(6 \%)$ could be killed by at least one of the 40 phages in the collection. These 3 UPEC strains, which originated from dogs, comprised 2 strains that yielded no plaques after initial incubation with sewage and 1 additional strain that was not used in the initial preparation of phage stocks.

\subsection{Relatively low susceptibility of faecal E. coli to phage}

The phage susceptibility of $7 E$. coli strains isolated from normal faeces was tested to investigate whether phages able to lyse UPEC were also able to lyse faecal E. coli strains presumed to be commensal. The 40 phages lysed on average $0.9 / 7(13 \%)$ faecal $E$. coli strains (range $0-71 \%$, median $14 \%$ ). Lysis of faecal $E$. coli strains was significantly less likely than lysis of UPEC strains (Holm's adjusted z test, $P=0.001$ ). The susceptibility of faecal $E$. coli to the 10 phages that lysed the most UPEC strains was similar to 


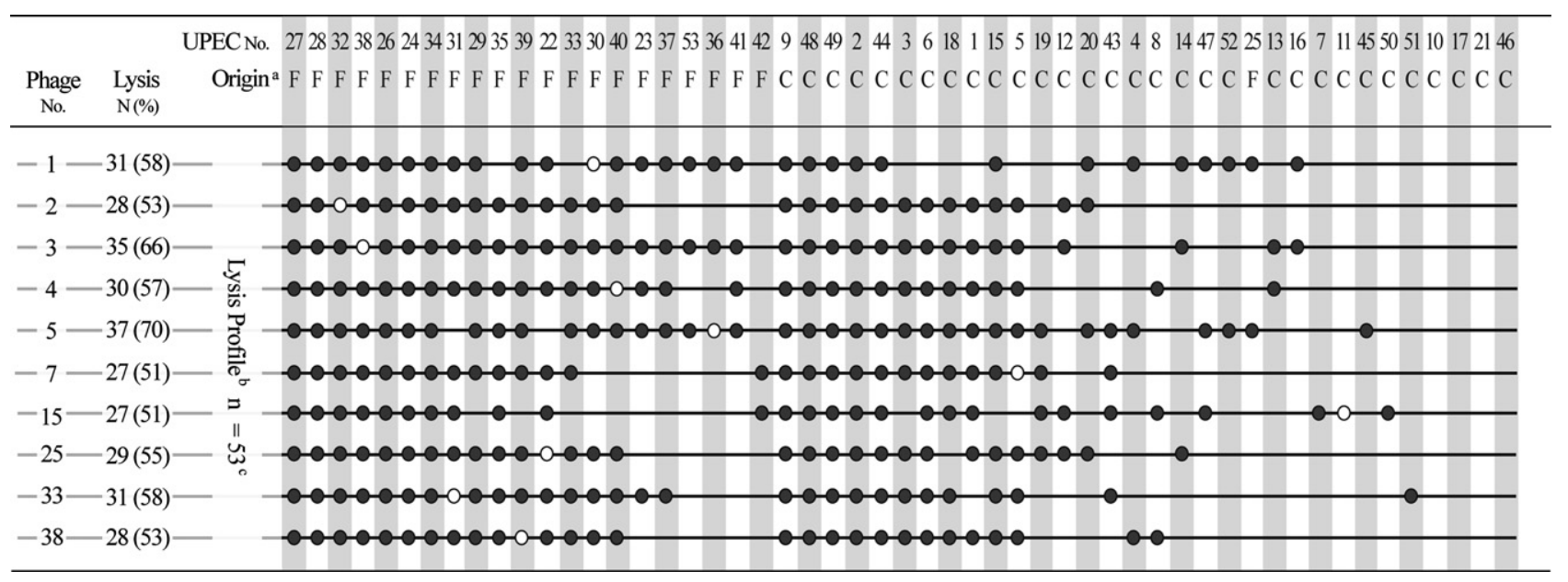

Fig. 1. Illustration of characteristics of UPEC strains and their lysis by the 10 phages with the broadest host range. (a) Species UPEC strain was isolated from: C: canine, F: feline. (b) Differences in lysis between 10 selected phages: $\bullet$ indicates that lysis was observed, a space indicates that no lysis was observed. $\bigcirc$ indicates that the phage was isolated from above UPEC strain. (c) Differences in lysis between the 10 phages were observed in 53 UPEC strains.

the susceptibility to the 30 other members of the phage collection. Of the 10 phages with the broadest UPEC host range, 7 (phages $3,4,5,7,15,25$ and 38 ) lysed $1 / 7$ faecal E. coli, one (phage 33) lysed $2 / 7$ faecal E. coli, and 2 (phages 1 and 2) lysed 3/7 faecal E. coli. Compared to other faecal $E$. coli that were lysed by $\leqslant 6 / 40$ phages, one faecal E. coli strain (Strain 135) appeared particularly susceptible to the phages in the collection. Considering once again the 10 phages with the broadest UPEC host range, strain 135 was lysed by 5 of the 7 that lysed a single faecal strain and by both of those that lysed 3/7 faecal strains. Strain 135 was also lysed by 6 of the other 30 phages in the collection.

\subsection{Characterisation of 5 'promising' phages}

Five phages (1-5) that showed a broad host range, lysing $\geqslant 53 \%$ UPEC isolates (Fig. 1), were characterised further. Electron microscopy revealed that all of these phages belonged to the order Caudovirales and the family Myoviridae (Büchen-Osmond, 2006). Phages 1-4 belonged to the morphotype A2 (Ackermann and Eisenstark, 1974) and had morphological similarity to lytic phage T4 (Fig. 2; Büchen-Osmond, 2006). These morphological findings were verified by sequence analysis. For each of the four T4-like phages a tail gene could be amplified using primers based on the T4 tail gene 18 (Tetart et al., 2001).

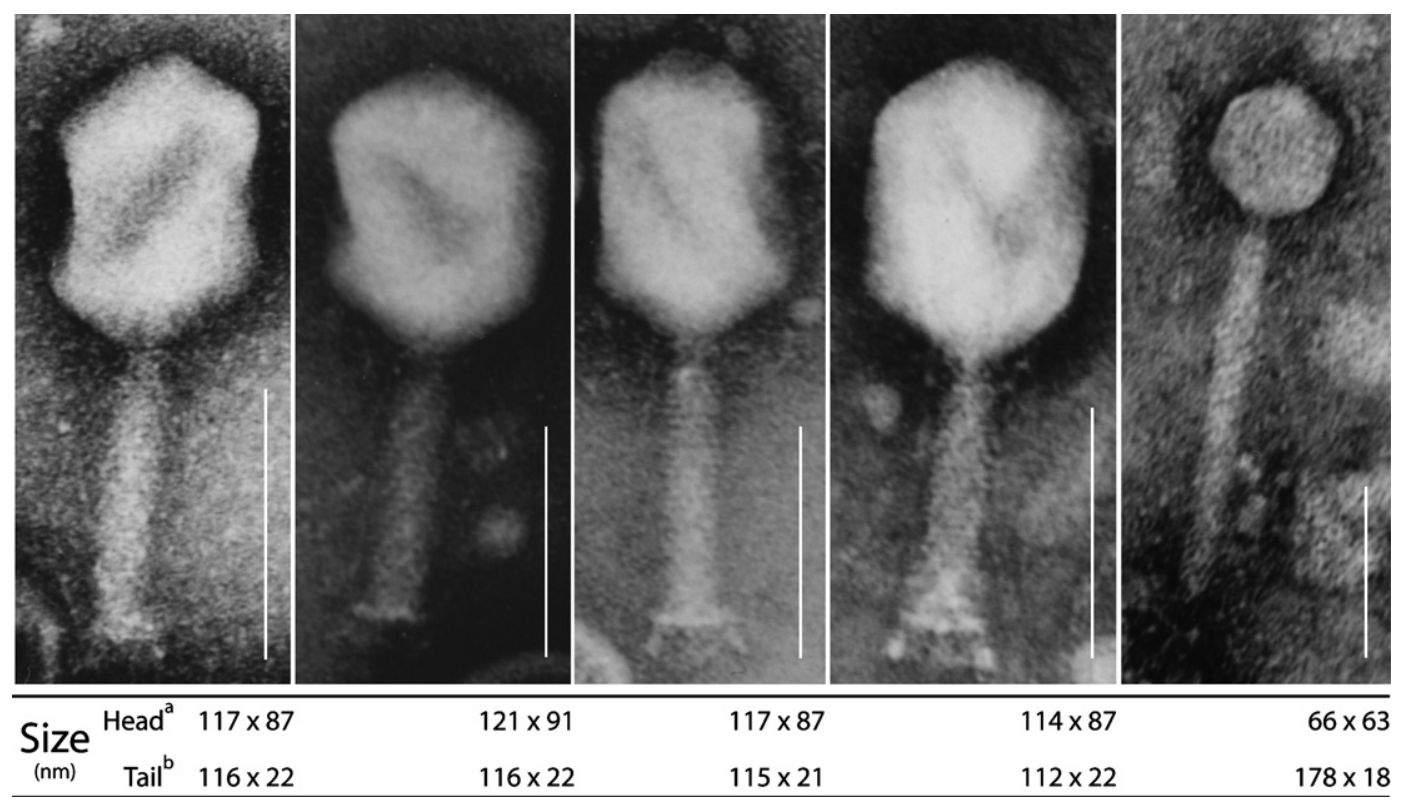

Fig. 2. Electron microscopic images of phages 1-5 (from left to right). UA staining. The white bar indicates $100 \mathrm{~nm}$. (a) Head size, apical measurement $\times$ side measurement. (b) Tail size, length $\times$ width. 


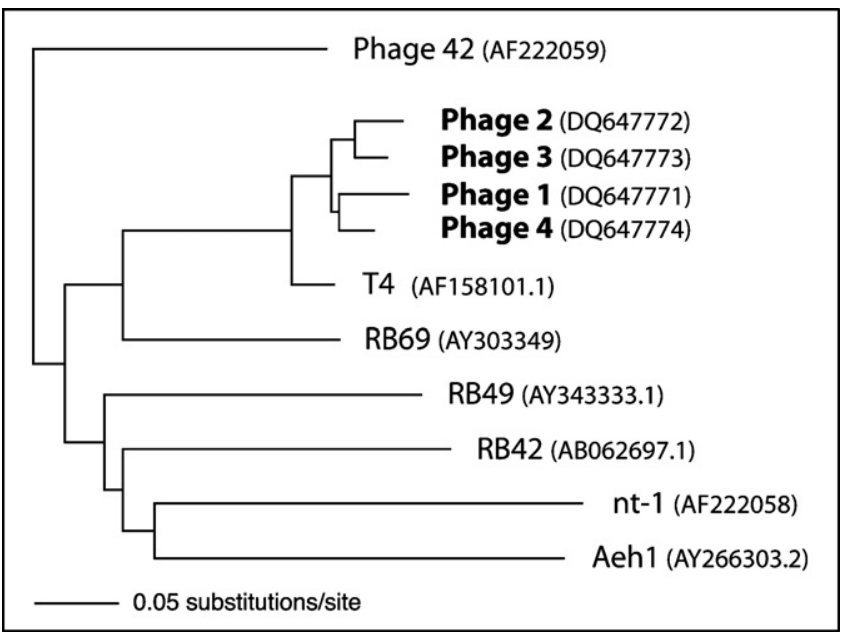

Fig. 3. Comparison of phages $1-4$ to phylogenetically well-characterised phages (Tetart et al., 2001). Accession numbers of gene sequences that were obtained from GenBank are given in brackets.

All sequences were unique, but highly similar (91-95\%) to each other. When comparing the tail gene sequences with sequences of 7 phylogenetically well-characterised T4-like phages (Tetart et al., 2001), these phages clustered closely with others belonging to the T-even group (T4 and RB69; Fig. 3). Phage 5 had a different morphology to phages $1-4$ (Fig. 2). It belonged to the morphotype A1 (Ackermann and Eisenstark, 1974) and had morphological similarity to temperate phage P2 (Büchen-Osmond, 2006). However, the tail of phage 5 appeared considerably longer than previously reported for P2 phages (Büchen-Osmond, 2006).

\section{Discussion and conclusions}

This study showed that naturally occurring phages, readily obtained by making a single visit to a sewage treatment plant, were able to lyse a large proportion of the canine and feline UPEC strains in our collection, at least in vitro. Individual phages were able to kill $17-72 \%$ of the UPEC strains in our collection. The 10 phages with the broadest host range each lysed more than half of all UPEC strains. Each of them had a distinct lysis profile and, taken together, they lysed $92 \%$ of the UPEC strains. This result is in marked contrast to a previously published study of E. coli UTIs in children (Drulis-Kawa et al., 2002), in which only 14 of 44 phages lysed more than $15 \%$ of the UPEC strains studied. Only 3 phages studied by DrulisKawa et al. (2002) lysed more than $50 \%$ of UPEC strains. Phages used in the previous study were selected from a hospital collection of $E$. coli phages. It is possible that our selective propagation of phages on UPEC improved our overall lysis results. However, it cannot be excluded at this stage that UPEC isolated from cats and dogs are, in general, more susceptible to phage lysis than are UPEC isolated from children.

Our results indicate that it may be possible to treat UTIs caused by a large variety of UPEC strains with one prepa- ration containing a mixture of phages that have, overall, a relatively broad host range. Previous applications of such phage combinations (so-called 'phage cocktails') in other disorders have been described as highly successful (Kutter and Sulakvelidze, 2005). The use of a 'cocktail' may not only increase the proportion of UPEC strains that can be lysed, and minimize the development of resistance to phages, but it may also allow recombination of adhesin structures (Kutter et al., 1995, 2005; Tetart et al., 1998). Thus, new, "naturally recombinant" phages with an extended host range may be created (Abe et al., 2007).

One of the concerns when using naturally occurring phages is that these phages may have the ability to transfer potentially deleterious genes to bacteria (Boyd and Brussow, 2002; Wagner and Waldor, 2002). These so-called transducing phages are almost exclusively temperate, that is, they have the ability to integrate their genome into the host bacterial genome (Birge, 2000). In addition to their transducing potential, temperate phages are considered inappropriate for phage therapy because these phages may not lyse bacteria consistently (Lwoff, 1953). In this study, EM and DNA sequencing of a tail tube gene were applied to 5 phages with a promising lysis profile to investigate whether these naturally occurring phages are comparable to previously studied lytic or temperate phages. Four of these 5 phages were demonstrated to be T4-like (BüchenOsmond, 2006), belonging to the T-even phage group (Tetart et al., 2001). These 4 phages are considered to be lytic phages that are unable to integrate their viral genome into the host bacterial genome. Therefore, they are considered suitable candidates for future in vivo therapeutic trials and suitable candidates for inclusion in 'phage cocktails'. A fifth phage with a very promising lysis profile that had a morphotype similar to temperate phage $\mathrm{P} 2$ is at present considered an inappropriate candidate for inclusion in the therapeutic phage preparations. Inclusion in future phage cocktails may be considered if subsequent studies can show that this phage: (i) lyses UPEC consistently; and (ii) does not encode deleterious traits.

Several previous studies have shown that phages readily cross physiological barriers, irrespective of the route of administration. (Biswas et al., 2002; Dubos et al., 1943; Geier et al., 1973; Reynaud et al., 1992; Smith and Huggins, 1982; Weber-Dabrowska et al., 1987). The ability of phages to disperse within virtually all body compartments is thought to facilitate oral phage therapy of UTIs (Weber-Dabrowska et al., 1987). However, achievement of therapeutic phage titres at distant sites of infection may be challenging after oral phage administration. The ability of phages to disperse throughout the body also increases the likeliness that 'therapeutic' phages, even when administered parenterally, will encounter and perhaps lyse commensal gastrointestinal bacteria. Recent studies in mice (Chibani-Chennoufi et al., 2004) and humans (Bruttin and Brussow, 2005) indicate that commensal bacteria susceptible to phages in vitro are in vivo largely resistant to orally administered phages. Nonetheless, it was considered desir- 
able to investigate the phage susceptibility of commensal E. coli strains in vitro. Phages tested during this in vitro trial lysed significantly more UPEC strains than faecal E. coli strains. In fact, only one of the faecal strains tested showed a phage susceptibility that was comparable to the average susceptibility of UPEC. A likely explanation for this difference in susceptibility to lysis is that significantly more UPEC than faecal E. coli expressed the specific receptors necessary for phage attachment. The faecal strains were isolated from animals without signs of gastrointestinal disease or UTI, and it is considered likely that most of them were gastrointestinal commensals. Commensal E. coli and UPEC commonly belong to different phylogenetic groups and faecal $E$. coli strains often lack virulence traits that are present in UPEC (Johnson et al., 2003; Johnson and Russo, 2002; Whittam et al., 1989). By propagation of phage on UPEC we may have selected for phages that recognise receptors selectively expressed by UPEC, but not by commensal (faecal) E. coli.

In conclusion, this study has shown that a diversity of phages able to lyse clinically-relevant canine and feline UPEC isolates, at least in vitro, can readily be found in nature. Phage therapy of canine and feline UTIs - and of other serious diseases caused by UPEC strains and their close relatives - may therefore be feasible. Further work is needed to investigate whether these in vitro findings translate into clinically relevant in vivo efficacy.

\section{Acknowledgements}

The authors wish to acknowledge Dr. Jasna Rakonjac, who kindly provided scientific and technical advice and commented on the manuscript. We also wish to thank Doug Hopcroft and Raymond Bennett, Dr. Alasdair Noble, and Dianne Knight who helped with Electron Microscopy, statistical analysis and DNA sequencing, respectively. Special thanks also to all UPEC strains providers. This work was supported by grants of the ECVIM-CA and the Waltham Foundation.

\section{References}

Abe, M., Izumoji, Y., Tanji, Y., 2007. Phenotypic transformation including host-range transition through superinfection of T-even phages. FEMS Microbiol. Lett. 269, 145-152.

Ackermann, H.W., DuBow, M.S., 1987. Viruses of Prokaryotes. Volume I. General Properties of Bacteriophages. CRC Press, Boca Raton, FL.

Ackermann, H.W., Eisenstark, A., 1974. The present state of phage taxonomy. Intervirology 3, 201-219.

Alisky, J., Iczkowski, K., Rapoport, A., Troitsky, N., 1998. Bacteriophages show promise as antimicrobial agents. J. Infect. 36, 5-15.

Barrow, P., Lovell, M., Berchieri Jr., A., 1998. Use of lytic bacteriophage for control of experimental Escherichia coli septicemia and meningitis in chickens and calves. Clin. Diagn. Lab. Immunol. 5, 294-298.

Bartges, J.W., 2005. Urinary tract infections. In: Ettinger, S.J., Feldman, E.C. (Eds.), Textbook of Veterinary Internal Medicine. Elsevier Saunders, St. Louis, Missouri, pp. 1800-1808.

Birge, E.A., 2000. Bacterial and Bacteriophage Genetics, fourth ed. Springer-Verlag, New York.
Biswas, B., Adhya, S., Washart, P., Paul, B., Trostel, A.N., Powell, B., Carlton, R., Merril, C.R., 2002. Bacteriophage therapy rescues mice bacteremic from a clinical isolate of vancomycin-resistant Enterococcus faecium. Infect. Immun. 70, 204-210.

Boyd, E.F., Brussow, H., 2002. Common themes among bacteriophageencoded virulence factors and diversity among the bacteriophages involved. Trends Microbiol. 10, 521-529.

Bruttin, A., Brussow, H., 2005. Human volunteers receiving Escherichia coli phage T4 orally: a safety test of phage therapy. Antimicrob. Agents Chemother. 49, 2874-2878.

Büchen-Osmond, C., 2006. ICTVdB - The Universal Virus Database. In Büchen-Osmond, C.E. (Ed.), ICTVdB - The Universal Virus Database, Version 4 (New York, USA, ICTVdB Management, Mailman School of Public Health, Columbia University, New York, NY, USA).

Chenna, R., Sugawara, H., Koike, T., Lopez, R., Gibson, T.J., Higgins, D.G., Thompson, J.D., 2003. Multiple sequence alignment with the Clustal series of programs. Nucl. Acids Res. 31, 3497-3500.

Chibani-Chennoufi, S., Sidoti, J., Bruttin, A., Kutter, E., Sarker, S., Brussow, H., 2004. In vitro and in vivo bacteriolytic activities of Escherichia coli phages: implications for phage therapy. Antimicrob. Agents Chemother. 48, 2558-2569.

Cohn, L.A., Gary, A.T., Fales, W.H., Madsen, R.W., 2003. Trends in fluoroquinolone resistance of bacteria isolated from canine urinary tracts. J. Vet. Diagn. Invest. 15, 338-343.

Comer, K.M., Ling, G.V., 1981. Results of urinalysis and bacterial culture of canine urine obtained by antepubic cystocentesis, catheterization, and the midstream voided methods. J. Am. Vet. Med. Assoc. 179, 891895.

Dawson, B., Trapp, R., 1994. Basic and Clinical Biostatistics, second ed. Appleton and Lange, Norwalk, CT, USA.

Drazenovich, N., Ling, G.V., Foley, J., 2004. Molecular investigation of Escherichia coli strains associated with apparently persistent urinary tract infection in dogs. J. Vet. Intern. Med. 18, 301-306.

Drulis-Kawa, Z., Weber-Dabrowska, B., Lewczyk, E., Jankowski, S., Doroszkiewicz, W., 2002. The sensitivity of the uropathogenic Escherichia coli strains to antibiotics, bacteriophages and bactericidal serum activity. Pol. Merkuriusz Lek. 13, 470-472 (in Polish).

Dubos, R.J., Straus, J.H., Pierce, C., 1943. The multiplication of bacteriophage in vivo and its protective effect against an experimental infection with Shigella dysenteriae. J. Exp. Med. 78, 161-168.

Foxman, B., 2002. Epidemiology of urinary tract infections: incidence, morbidity, and economic costs. Am. J. Med. 113 (Suppl. 1A), 5S-13S.

Freitag, T., Squires, R.A., Schmid, J., Elliott, J., 2005. Feline uropathogenic Escherichia coli from Great Britain and New Zealand have dissimilar virulence factor genotypes. Vet. Microbiol. 106, 79-86.

Freitag, T., Squires, R.A., Schmid, J., Elliott, J., Rycroft, A.N., 2006. Antibiotic sensitivity profiles do not reliably distinguish relapsing or persisting infections from reinfections in cats with chronic renal failure and multiple diagnoses of Escherichia coli urinary tract infection. J. Vet. Intern. Med. 20, 245-249.

Geier, M.R., Trigg, M.E., Merril, C.R., 1973. Fate of bacteriophage lambda in non-immune germ-free mice. Nature 246, 221-223.

Huff, W.E., Huff, G.R., Rath, N.C., Balog, J.M., Donoghue, A.M., 2003. Bacteriophage treatment of a severe Escherichia coli respiratory infection in broiler chickens. Avian Dis. 47, 1399-1405.

Huff, W.E., Huff, G.R., Rath, N.C., Balog, J.M., Donoghue, A.M., 2004. Therapeutic efficacy of bacteriophage and Baytril (enrofloxacin) individually and in combination to treat colibacillosis in broilers. Poult. Sci. 83, 1944-1947.

Johnson, J.R., Kaster, N., Kuskowski, M.A., Ling, G.V., 2003. Identification of urovirulence traits in Escherichia coli by comparison of urinary and rectal E. coli isolates from dogs with urinary tract infection. J. Clin. Microbiol. 41, 337-345.

Johnson, J.R., Russo, T.A., 2002. Extraintestinal pathogenic Escherichia coli: "the other bad E. coli". J. Lab. Clin. Med. 139, 155-162.

Kutter, E., Gachechiladze, K., Poglazov, A., Marusich, E., Shneider, M., Aronsson, P., Napuli, A., Porter, D., Mesyanzhinov, V., 1995. Evolution of T4-related phages. Virus Genes 11, 285-297. 
Kutter, E., Raya, R., Carlson, K., 2005. Molecular mechanisms of phage infection. In: Kutter, E., Sulakvelidze, A. (Eds.), Bacteriophage As Antibiotics: Molecular Biology and Applications. CRC Press, Boca Raton, FL, pp. 165-213.

Kutter, E., Sulakvelidze, A., 2005. Bacteriophage as Antibiotics: Molecular Biology and Applications. CRC Press, Boca Raton, FL.

Ling, G.V., 2000. Bacterial infections of the urinary tract. In: Ettinger, S.J., Feldman, E.C. (Eds.), Textbook of Veterinary Internal Medicine. W.B. Saunders, Philadelphia, PA, pp. 1678-1686.

Ludbrook, J., 1998. Multiple comparison procedures updated. Clin. Exp. Pharmacol. Physiol. 25, 1032-1037.

Lwoff, A., 1953. Lysogeny. Bacteriol. Rev. 17, 269-337.

Manges, A.R., Johnson, J.R., Foxman, B., O'Bryan, T.T., Fullerton, K.E., Riley, L.W., 2001. Widespread distribution of urinary tract infections caused by a multidrug-resistant Escherichia coli clonal group. N. Engl. J. Med. 345, 1007-1013.

Mulvey, M.A., Schilling, J.D., Hultgren, S.J., 2001. Establishment of a persistent Escherichia coli reservoir during the acute phase of a bladder infection. Infect. Immun. 69, 4572-4579.

Perepanova, T.S., Darbeeva, O.S., Kotliarova, G.A., Kondrat'eva, E.M., Maiskaia, L.M., Malysheva, V.F., Baiguzina, F.A., Grishkova, N.V., 1995, The efficacy of bacteriophage preparations in treating inflammatory urologic diseases. Urol. Nefrol. (Mosk.), 14-17 (in Russian).

Quinn, P.J., Carter, M.E., Markey, B., Carter, G.R., 1994. Clinical Veterinary Microbiology. Wolfe Publishing.

Raettig, H., 1958, Bakteriophagie, 1917-1956; Zugleich ein Vorschlag zur Dokumentation wissenschaftlicher Literatur. Gustav Fischer Verlag, Stuttgart (in German).

Reynaud, A., Cloastre, L., Bernard, J., Laveran, H., Ackermann, H.W., Licois, D., Joly, B., 1992. Characteristics and diffusion in the rabbit of a phage for Escherichia coli 0103. Attempts to use this phage for therapy. Vet. Microbiol. 30, 203-212.

Russo, T.A., Johnson, J.R., 2003. Medical and economic impact of extraintestinal infections due to Escherichia coli: focus on an increasingly important endemic problem. Microbes Infect. 5, 449-456.

Sambrook, J., Russell, D.W., 2001. Molecular Cloning, third ed. Cold Spring Harbor Laboratory Press, Cold Spring Harbor, New York.
Schilling, J.D., Lorenz, R.G., Hultgren, S.J., 2002. Effect of trimethoprimsulfamethoxazole on recurrent bacteriuria and bacterial persistence in mice infected with uropathogenic Escherichia coli. Infect. Immun. 70, 7042-7049.

Seguin, M.A., Vaden, S.L., Altier, C., Stone, E., Levine, J.F., 2003. Persistent urinary tract infections and reinfections in 100 dogs (19891999). J. Vet. Intern. Med. 17, 622-631.

Slopek, S., Weber-Dabrowska, B., Dabrowski, M., Kucharewicz-Krukowska, A., 1987. Results of bacteriophage treatment of suppurative bacterial infections in the years 1981-1986. Arch. Immunol. Ther. Exp. (Warsz.) 35, 569-583.

Smith, H.W., Huggins, M.B., 1982. Successful treatment of experimental Escherichia coli infections in mice using phage: its general superiority over antibiotics. J. Gen. Microbiol. 128, 307-318.

Smith, H.W., Huggins, M.B., 1983. Effectiveness of phages in treating experimental Escherichia coli diarrhoea in calves, piglets and lambs. J. Gen. Microbiol. 129 (Pt 8), 2659-2675.

Swofford, D.L., 2003. PAUP*. Phylogenetic Analysis Using Parsimony ( ${ }^{*}$ and other Methods) (Sunderland, Massachusetts, Sinauer Associates).

Tetart, F., Desplats, C., Krisch, H.M., 1998. Genome plasticity in the distal tail fiber locus of the T-even bacteriophage: recombination between conserved motifs swaps adhesin specificity. J. Mol. Biol. 282, 543-556.

Tetart, F., Desplats, C., Kutateladze, M., Monod, C., Ackermann, H.W., Krisch, H.M., 2001. Phylogeny of the major head and tail genes of the wide-ranging T4-type bacteriophages. J. Bacteriol. 183, 358-366.

Wagner, P.L., Waldor, M.K., 2002. Bacteriophage control of bacterial virulence. Infect. Immun. 70, 3985-3993.

Weber-Dabrowska, B., Dabrowski, M., Slopek, S., 1987. Studies on bacteriophage penetration in patients subjected to phage therapy. Arch. Immunol. Ther. Exp. (Warsz.) 35, 563-568.

Weber-Dabrowska, B., Mulczyk, M., Gorski, A., 2000. Bacteriophage therapy of bacterial infections: an update of our institute's experience. Arch. Immunol. Ther. Exp. (Warsz.) 48, 547-551.

Whittam, T.S., Wolfe, M.L., Wilson, R.A., 1989. Genetic relationships among Escherichia coli isolates causing urinary tract infections in humans and animals. Epidemiol. Infect. 102, 37-46. 